\section{Effect of Volatile Compounds Produced by Selected Bacterial Endophytes in Promoting Plant Growth}

\author{
Asha Maheshwari \\ Bioservices, 1845 Elm Hill Pike, Nashville, TN 37210
}

\section{Margaret Mmbaga, Bandana Bhusal, and Christine Ondzighi-Assoume \\ Department of Agricultural and Environmental Sciences, Tennessee State University, Nashville, TN 37209}

Additional index words. biofertilizers, endophytes, tomatoes, sweet pepper, Arabidopsis, cucumbers, biocontrols

\begin{abstract}
Bacterial endophytes selected for their capability to suppress diverse fungal pathogens in vitro and in greenhouse studies have been shown to promote plant growth. The effect of volatile compounds emitted by selected bacteria on plant growth in Arabidopsis thaliana, tomato (Solanum lycopersicum), sweet pepper (Capsicum annuum), and cucumbers (Cucumis sativus) was evaluated on container-grown plants nested above bacterial cultures, with roots exposed to the volatiles without direct contact between bacterial cells and the plant roots. Significant increases in plant growth were observed in plant height, root length, leaf size, fresh weight, and chlorophyll content in all plants tested. Although diverse chemical compounds may be involved in promoting plant growth, including volatile and nonvolatile compounds, observations in this study have implications for the potential role of the selected bacteria in plant production as biofertilizers and biopesticides.
\end{abstract}

Plants interact with diverse microorganisms in their natural surroundings, with some organisms colonizing plant internal tissues as endophytes without causing any harm to their host (Joshua and Mmbaga, 2020; Khan et al., 2016; Li et al., 2016; Petrini, 1991). Endophytes are ubiquitous and they function in a variety of ways, including plant growth promotion and protection against pathogens (Joshua and Mmbaga, 2020). Some of the possible mechanisms of action are the production of growth-promoting hormones; cell wall-degrading enzymes for plant protection against pathogens; production of antibiotics, 1aminocyclopropane-1-carboxylate deaminase, and siderophores for nutrient acquisition; and volatile compounds that may function in various ways (D'Alessandro et al., 2014; Khan et al., 2016; Li et al., 2016, 2017; Loaces et al., 2011). Several bacterial endophytes have been

Received for publication 8 Jan. 2021. Accepted for publication $24 \mathrm{Feb} .2021$.

Published online 7 September 2021.

We appreciate the feedback, input, and support provided by Warren Shafer, Greg Venburg, Mark Beach, Peter Petracek, Marci Surpin, and Dale Wilson at Valent BioSciences LLC, as well as the assistance with statistical analysis provided by Xiangyao Su at Astex Pharmaceuticals Inc.

M.M. is the corresponding author. E-mail: Mmmbaga@tnstate.edu.

This is an open access article distributed under the CC BY-NC-ND license (https://creativecommons. org/licenses/by-nc-nd/4.0/). isolated and identified in our earlier studies (Joshua and Mmbaga, 2020; Mmbaga et al., 2008). In our previous studies, endophytes isolated from flowering dogwood, papaya, and common beans were shown to exhibit biocontrol activities against fungal diseases such as powdery mildew of flowering dogwood (Mmbaga et al., 2008, 2016; Rotich, 2015; Rotich et al., 2019), phytophthora blight of pepper (Bhusal and Mmbaga, 2020; Irabor and Mmbaga, 2017; Mmbaga et al., 2018a), and macrophomina root rot (Joshua, 2017; Joshua and Mmbaga, 2020; Mmbaga et al., 2018b). In addition, the selected bacterial isolates applied to plants using root drenching, foliage sprays, and seed treatment displayed plant growth-promoting abilities.

Previous studies have reported that endophytic microorganisms often release small and low-molecular weight volatile organic compounds (VOCs) that diffuse freely in aboveground and belowground environments (Schulz-Bohm et al., 2017; Vespermann et al., 2007). To date, VOCs produced by Bacillus, Pseudomonas, Enterobacter, and Streptomyces have been reported to stimulate plant growth and induce resistance against phytopathogens (Asari et al., 2016; Cordovez et al., 2015, 2018; D'Alessandro et al., 2014; Park et al., 2015; Ryu et al., 2003; Tahir et al., 2017a, 2017b). Some studies have reported the ability of endophytic microbial VOCs to activate induced systemic resistance (Cordovez et al., 2015, 2018; Han et al.,
2006; Park et al., 2015; Ryu et al., 2004; Syed-Ab-Rahman et al., 2019; Vespermann et al., 2007), and induced plant growth and salt tolerance (Fan et al., 2020; Li et al., 2017).

The phenomenon of plant growth promotion by microbial volatiles was first demonstrated in Arabidopsis thaliana by Ryu et al. (2003, 2004). Root-associated bacterial genera including Azospirillum, Arthrobacter, Azotobacter, Bacillus, Burkholderia, Erwinia, Enterobacter, Klebsiella, Paenibacillus, Pantoea, Pseudomonas, Serratia, and Xanthomonas are among the main rhizobacteria investigated for promotion of plant growth, and some of these have already been deployed as biofertilizers (Fan et al., 2020; Li et al., 2017). Volatile compounds such as 2-pentylfuran, indole, hexanol, and pentadecane were shown to enhance growth of A. thaliana (Blom et al., 2011a; Zou et al., 2010). Park et al. (2015) identified 13tetradecadien-1-ol, 2-butanone, and 2-methyln-1-tridecene, emitted by Pseudomonas fluorescens SS101, that promoted tobacco plant growth. Most recently, albuterol and 1, 3-propanediol from $B$. subtilis SYST2 have been identified for their ability to promote plant growth in tomatoes (Tahir et al., 2017a). Previous studies focused mainly on VOCs derived from plant growth-promoting rhizobacteria. The main objectives of our study were to investigate selected bacterial endophytes isolated from stem and root tissues of diverse plants for plant growth promotion of Arabidopsis thaliana, tomatoes (Solanum lycopersicum), sweet peppers (Capsicum annuum), and cucumbers (Cucumis sativus) exposed to VOCs from selected bacterial endophytes.

\section{Materials and Methods}

Bacterial isolates. Eight selected endophytic bacterial isolates used in this study (Table 1) were isolated previously from healthy plants. Cultures for long-term storage were prepared in $25 \%$ glycerol stocks and stored at $-80^{\circ} \mathrm{C}$; actively growing cultures were maintained routinely in Luria-Bertani (LB) agar/broth at $27 \pm 2{ }^{\circ} \mathrm{C}$. Cultures used in this study were grown overnight in LB agar/broth at $27 \pm 2{ }^{\circ} \mathrm{C}$ and their concentration was adjusted to $\approx 10^{8} \mathrm{cfu} / \mathrm{mL}$. Mixtures of bacterial isolates were evaluated to identify potential synergism between isolates. All possible combinations of isolates were evaluated (Table 2). The isolates were grown separately and mixed $1: 1(\mathrm{v} / \mathrm{v})$ before inoculation and tested on sweet pepper only.

Plant material and growth conditions. To investigate the effect of VOCs produced by the selected bacterial endophytes, two sets of experiments were conducted in 1) in vitro plate experiments for wild-type Arabidopsis thaliana 'Columbia-0' and 2) pot experiments for tomatoes ( $S$. lycopersicum) 'Rutgers', sweet peppers (C. annuum) 'California Wonder', and cucumbers (C. sativus) 'Space Saver' (Table 2). 
Table 1. Bacterial endophytes used to evaluate bacteria-emitted volatile compounds on plant growth promotion.

\begin{tabular}{llll}
\hline $\begin{array}{l}\text { Bacterial } \\
\text { endophytes }\end{array}$ & \multicolumn{1}{c}{ Original source } & \multicolumn{1}{c}{ Taxon } & \multicolumn{1}{c}{ Reference } \\
\hline B17A & Cornus florida leaf & Stenotrophomonas sp. & Mmbaga et al. (2008) \\
B17B & C. florida leaf & Serratia marcescens & Mmbaga et al. (2008) \\
IMC8 & C. florida leaf & Bacillus thuringiensis & Mmbaga et al. (2008) \\
A2B1 & C. florida stem & B. thuringiensis & Mmbaga et al. (2008) \\
PS & Carica papaya stem & B. vallismortis & Joshua and Mmbaga (2020) \\
PSL & Carica papaya leaf & B. amyloliquefaciens & Joshua and Mmbaga (2020) \\
Prt & Carica papaya root & B. subtilis & Joshua and Mmbaga (2020) \\
$\mathrm{E}$ & Phaseolus vulgaris roots & Enterobacter sp. & Joshua and Mmbaga (2020) \\
\hline
\end{tabular}

Table 2. Evaluation of bacteria endophytes for volatile compounds that promote plant growth in root and shoot growth in four plant species.

\begin{tabular}{lcccc}
\hline & \multicolumn{4}{c}{ Growth promotion evaluated on different plant species $^{\mathrm{y}}$} \\
\cline { 2 - 5 } Bacterial isolates $^{\mathrm{z}}$ & Arabidopsis & Tomato & Sweet Pepper & Cucumber $^{-}$ \\
\hline B17A & $\checkmark$ & $\checkmark$ & $\checkmark$ & $\checkmark$ \\
B17B & $\checkmark$ & $\checkmark$ & $\checkmark$ & $\checkmark$ \\
IMC8 & $\checkmark$ & $\checkmark$ & $\checkmark$ & $\checkmark$ \\
PSL & $\checkmark$ & $\checkmark$ & $\checkmark$ & $\checkmark$ \\
PS & $\checkmark$ & $\checkmark$ & - & $\checkmark$ \\
Prt & $\checkmark$ & $\checkmark$ & - & - \\
A2B1 & $\checkmark$ & - & - & - \\
E & - & - & $\checkmark$ & - \\
IMC8 + PS & - & - & $\checkmark$ & - \\
IMC8 + PSL & - & - & $\checkmark$ & - \\
PS + PSL & - & $\checkmark$ & $\checkmark$ & - \\
IMC8 + PS + PSL & & - & $\checkmark$ & $\checkmark$
\end{tabular}

$\overline{{ }^{\mathrm{z}} \text { Bacterial isolates tested for growth promotion: B17A, Stenotrophomonas sp.; B17B, Serratia marces- }}$ cens; IMC8, Bacillus thuringiensis; A2B1, B. thuringiensis; PS, B. vallismortis; PSL, B. amyloliquefaciens; Prt, B. subtilis; and E, Enterobacter sp.

${ }^{\mathrm{y}}$ Plant species-bacterial isolate combinations tested $(\mathcal{})$ or not tested $(-)$ on different plant species.

Effect of bacterial volatiles on A. thaliana growth. A. thaliana seeds were surface-sterilized with $10 \%$ ethanol for $10 \mathrm{~min}$ and $10 \%$ sodium hypochlorite for $20 \mathrm{~min}$, and rinsed subsequently four to five times with sterile distilled water. The surface-sterilized seeds were then placed in petri dishes containing half-strength Murashige and Skoog (MS) medium (Murashige and Skoog, 1962) (SigmaAldrich, St. Louis, MO) with $1.0 \%$ sucrose and $0.8 \%$ Phytagel (Sigma-Aldrich), and with the $\mathrm{pH}$ adjusted to 5.6. The seeds were vernalized in the dark for $48 \mathrm{~h}$ at $4{ }^{\circ} \mathrm{C}$ and then transferred to growth chambers (Percival Scientific, Perry, IA) maintained at 16$\mathrm{h}$ light/8-h dark cycles, at a temperature of 21 $\pm 1{ }^{\circ} \mathrm{C}$, and at $50 \%$ to $60 \%$ relative humidity. To examine the effect of bacterial VOCs on A. thaliana plant growth, an arrangement of three plates was set up as described by Cordovez et al. (2015). Two-day-old $A$. thaliana germinated seedlings were transferred to 100 $\mathrm{mm}$ petri dishes containing $40 \mathrm{~mL}$ MS media prepared as described. A day before the actual experiment, $50 \mu \mathrm{L}$ of overnight bacterial cultures $\left(\approx 10^{8} \mathrm{cfu} / \mathrm{mL}\right)$ was inoculated onto MS medium in a $35-\mathrm{mm}$ petri dish and incubated for $24 \mathrm{~h}$ at $27 \pm 2{ }^{\circ} \mathrm{C}$. The two petri dishes containing $A$. thaliana and bacterial culture were then placed inside a large (145$\mathrm{mm})$ petri dish without a lid and were sealed tightly with parafilm to contain the VOCs produced by the bacterial isolates, as shown in Fig. 1. Control treatments consisted of $A$. thaliana seedlings exposed to growth medium with no bacteria. The three plates were incubated vertically for $7 \mathrm{~d}$ at a 16h light/8-h dark cycle and at $21 \pm 1^{\circ} \mathrm{C}$. The experimental design had a replication of four plates of 10 seedlings each and treatments were arranged in a randomized complete block design. To measure the effect of VOCs on $A$. thaliana growth, fresh and dry biomass were measured after cultivation for $7 \mathrm{~d}$. Furthermore, root morphology was assessed qualitatively using a dissecting microscope.

Effect of bacterial volatiles on tomato, pepper, and cucumber seedlings. Seeds of tomato, sweet pepper, and cucumber were surface-sterilized with $70 \%$ ethanol for $30 \mathrm{~s}$ and $10 \%$ sodium hypochlorite for $10 \mathrm{~min}$, rinsed subsequently with sterile distilled water three to four times for $5 \mathrm{~min}$ each, and blotted dry using heat-sterilized paper towels. Seeds were then sown in pot experiments according to Tahir et al. (2017a), with minor modifications, using heat-sterilized Miracle-Gro ${ }^{\circledR}$ potting mix, and maintained in a growth chamber set at a 12 -h light/12-h dark photoperiod, at $28 \pm 2{ }^{\circ} \mathrm{C}$, and at $70 \%$ to $75 \%$ relative humidity. At $7 \mathrm{~d}$ after sowing, seedlings of the same size at the two-leaf stage were selected and transplanted into heat-sterilized Miracle-Gro ${ }^{\circledR}$ soil in plastic pots $(15-\times 4.5$ $\mathrm{cm}$ cups) that had 10 small holes $(2 \mathrm{~mm})$ made at the bottom, and were covered with sterile cheesecloth. Bacterial cultures (24 $\mathrm{h}$ old) grown in LB medium in 45-mm petri dishes were placed at the bottom of 13- $\times 7$ $\mathrm{cm}$ sterile glass Mason ${ }^{\circledR}$ jars, and plastic containers with tomato, pepper, and cucumber seedlings were fit tightly over the glass jars and sealed with parafilm to prevent the escape of VOCs. The holes at the bottom of the pots facilitated diffusion of VOCs produced by bacterial endophytes through soil onto the plant root system. Seedling roots exposed to sterile growth media with no bacteria were used as the control. The entire plant assembly was placed in a growth chamber (Percival Scientific) at a 12-h light/12-h dark photoperiod, at $28 \pm 2{ }^{\circ} \mathrm{C}$, and at $70 \%$ to $75 \%$ relative humidity. Treatments were arranged in a randomized complete block design with four replicates. Plants were harvested after $30 \mathrm{~d}$ and growth parameters such as shoot and root length, total fresh biomass, total dry biomass, and chlorophyll content were measured.

Root analysis. After $30 \mathrm{~d}$ of exposure of root systems to VOCs of different bacterial endophytes, the roots were washed carefully and thoroughly under running tap water to remove any traces of soil particles, then the influence of bacterial endophyte VOCs on the plant root systems was assessed. Each root system was untangled carefully and scanned at a grayscale with a resolution of 800 dots per inch on an Epson Perfection V850 pro scanner (Seiko EPSON Corporation, Japan). Acquired images from arabidopsis and tomato plants were subsequently analyzed using WinRHIZO pro (version 2008b; Reagents Instruments Inc., Quebec, Canada), and growth parameters such as root length, shoot length, root biomass, and total biomass were measured. Growth parameters for pepper and cucumber plants included plant height, root weight, leaf area, and chlorophyl content.

Statistical analysis. Experimental data generated in these studies were subjected to analysis of variance using SAS version 9.4 (SAS Institute, Cary, NC). Specific differences in treatment means were compared using the least significant difference test at $P \leq$ 0.05 . Treatments mean values $\pm \mathrm{SD}$ are presented. All experiments were repeated to confirm the results; data from the first experiment are presented.

\section{Results}

Effect of bacterial volatiles on A. thaliana plant growth. No detrimental symptoms were observed on the $A$. thaliana seedlings after 7 $\mathrm{d}$ of cultivation in triplate assays with bacterial isolates. Visual representation of the effect of bacterial endophyte VOCs on shoots and roots after $7 \mathrm{~d}$ of exposure is presented in Figs. 1 and 2. The VOCs produced by all tested bacterial endophytes stimulated growth of both shoots and roots of exposed plants even without any direct contact between the bacterial isolate and the plants (Figs. 1 and 2). The $A$. thaliana plants exposed to VOCs displayed increased biomass compared with controls, and visual observation was consistent with the measured shoot biomass (Fig. 2). The VOCs from all isolates increased biomass (shoot and root) of the exposed seedlings significantly $(P<0.0001)$ compared with the control that had no bacteria. Isolates B17B (Serratia marcescens) and PS (B. 


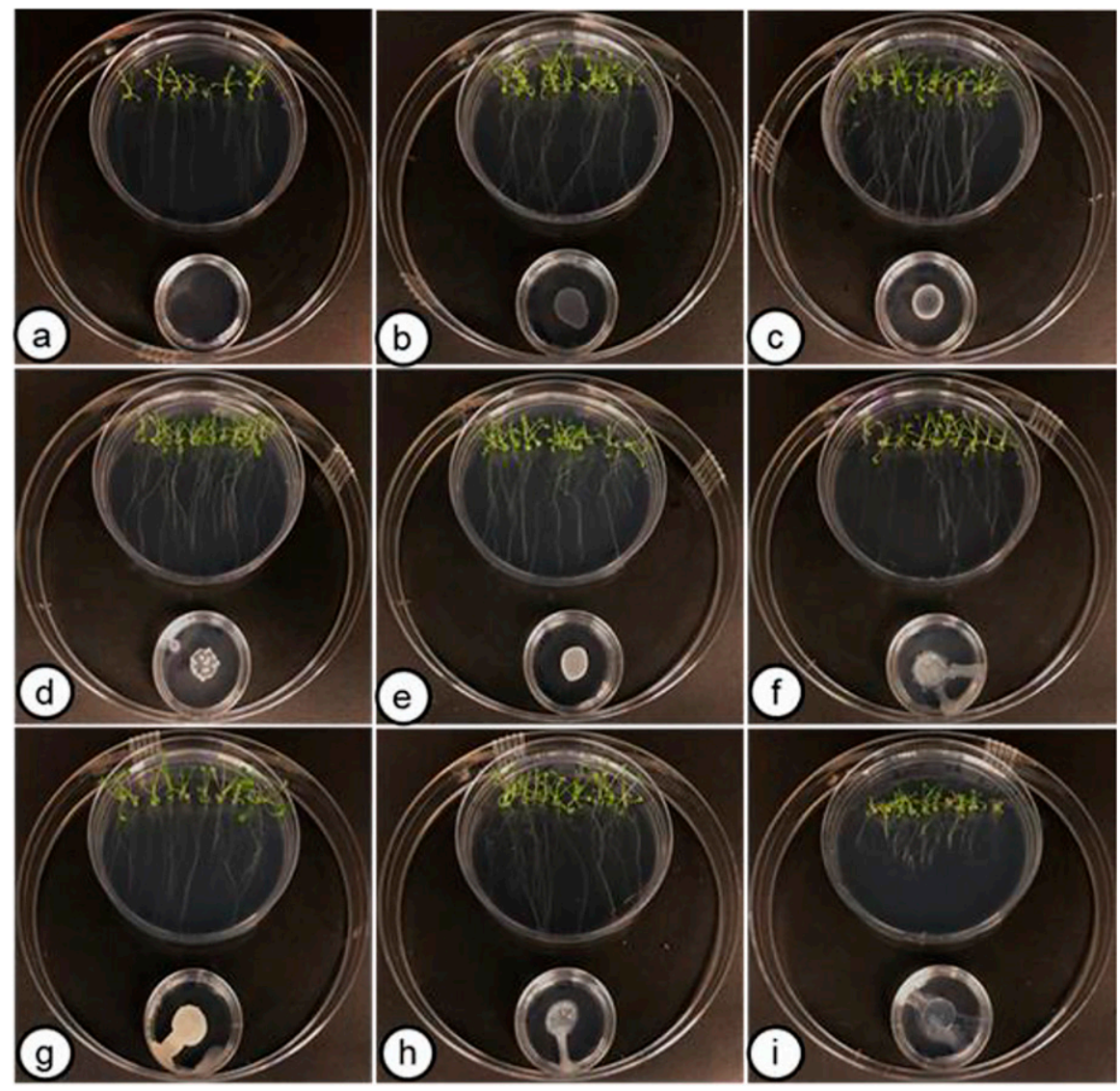

Fig. 1. Triplate assay to determine the effect of volatile organic compounds produced by bacterial endophytes on Arabidopsis thaliana plant growth. Plants were exposed to (a) control with sterile Murashige medium (MS), (b) B17A (Stenotrophomonas sp.) in MS, (c) B17B (Serratia marcescens) in MS, (d) IMC8 (Bacillus thuringiensis) in MS, (e) A2B1 (B. thuringiensis) in MS, (f) PS (B. vallismortis) in MS, (g) PSL (B. amyloliquefaciens) in MS, (h) Prt (B. subtilis) in MS, and (i) E (Enterobacter sp.) in MS.

A

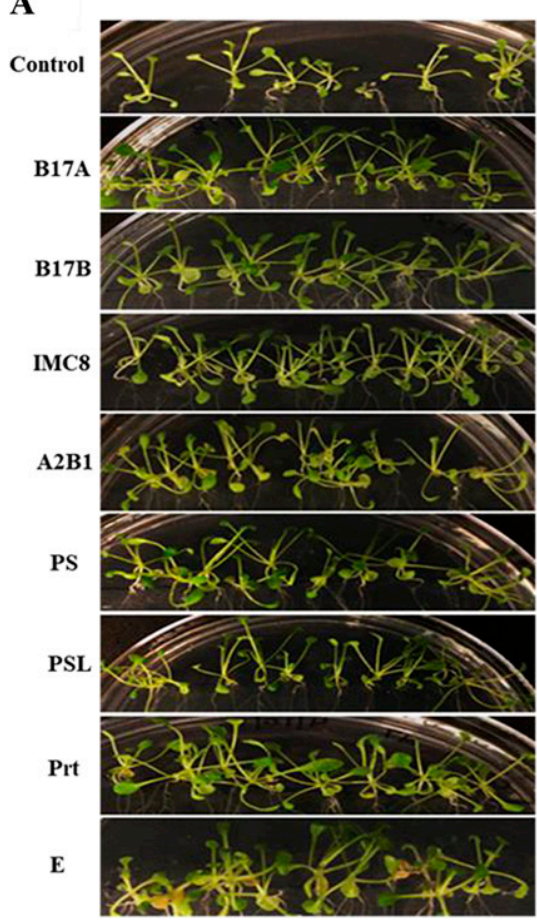

B
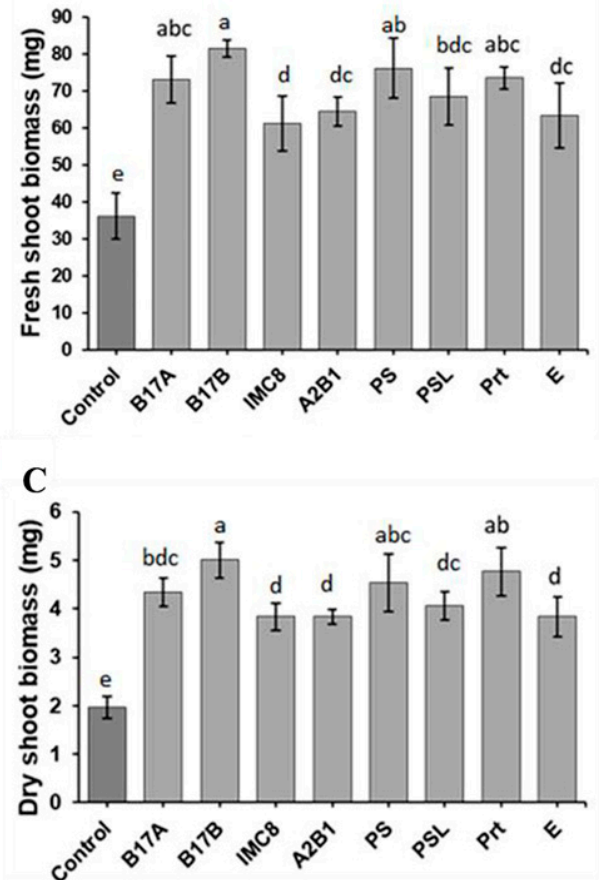

Fig. 2. Effect of volatile organic compounds produced by bacterial endophytes on the growth of Arabidopsis thaliana (10 seedlings per treatment in each replicate). (A) Visual representation of shoot growth after $7 \mathrm{~d}$ of exposure. (B) Fresh shoot biomass (mean $\pm \mathrm{SD}$ ). (C) Dry shoot biomass (mean $\pm \mathrm{SD}$ ). Column with the same letters on the bars indicate no significant difference according to the least significant difference test at $P \leq 0.05$. Similar results were obtained when the experiment was repeated. B17A, Stenotrophomonas sp.; B17B, Serratia marcescens; IMC8, Bacillus thuringiensis; A2B1, B. thuringiensis; PS, B. vallismortis; PSL, B. amyloliquefaciens; Prt, B. subtilis; E, Enterobacter sp. 
A

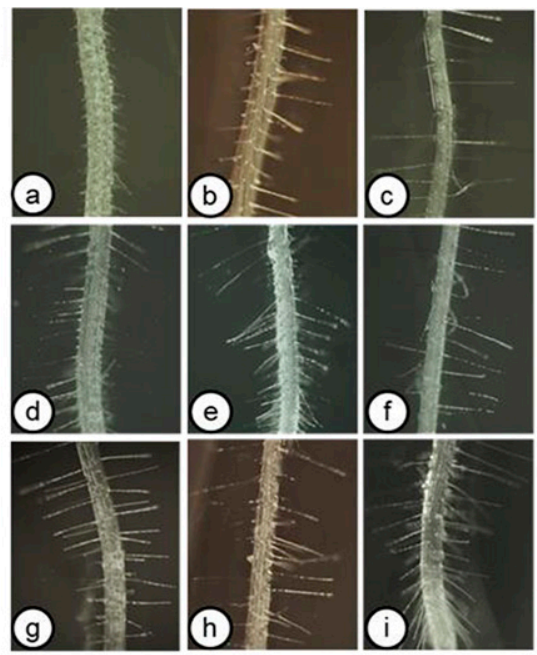

c

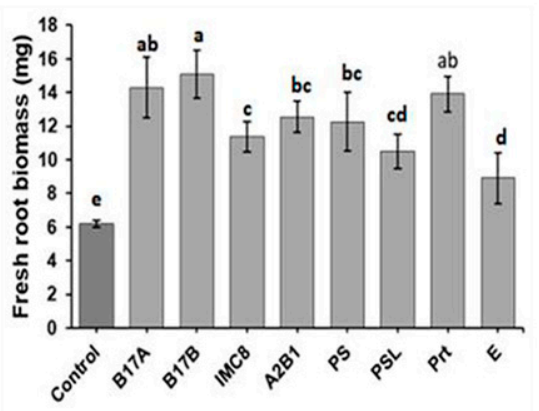

B

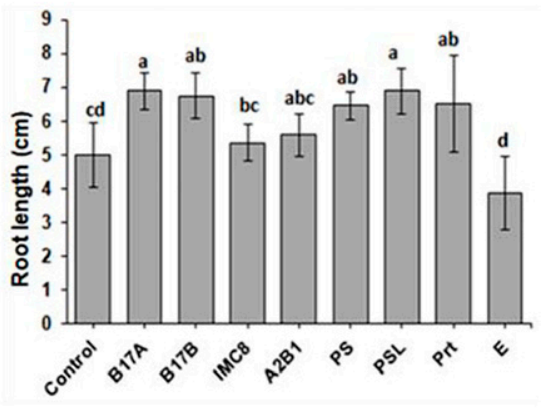

D

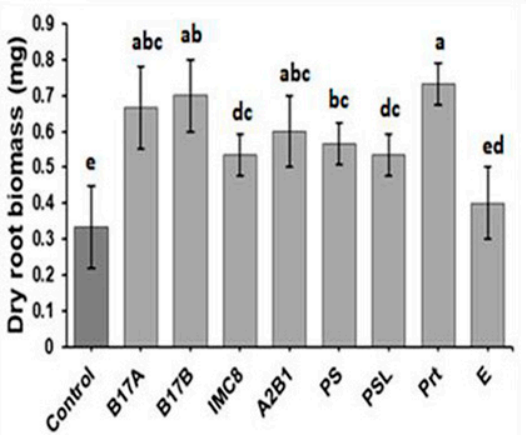

Fig. 3. Effect of volatile organic compounds produced by bacterial endophytes on Arabidopsis thaliana roots. (A) Microscopic (6×) pictures of roots exposed to (a) sterile Murashige medium (control), (b) B17A (Stenotrophomonas sp.), (c) B17B (Serratia marcescens), (d) IMC8 (Bacillus thuringiensis), (e) A2B1 (B. thuringiensis), (f) PS (B. vallismortis), (g) PSL (B. amyloliquefaciens), (h) Prt (B. subtilis), and (i) E (Enterobacter sp.). (B) Quantitative measurements of root length, (C) fresh root biomass and (D) dry root biomass.

vallismortis) produced a 2.3-fold increase in shoot biomass when compared with control plants (Fig. 2A and B), with isolates B17A (Stenotrophomonas sp.), B17B, A2B1 (Bacillus thuringiensis), PS, and Prt (B. subtilis) exhibiting more than a 2-fold increase in root (fresh and dry) biomass (Fig. 3C and D). Significant differences were also observed in primary root length when plants were exposed to volatiles (Fig. 3B). Along with an increase in primary root length, more lateral root development was observed in VOC-exposed plants (Fig. 3A) than in the controls. An exception to this observation was for plants exposed to VOCs of isolate E (Enterobacter sp.); the primary root length in these plants was shorter than in the control. However, the root biomass was greater as a result of lateral root branching (Figs. 1 and $3 \mathrm{~A}$ ). Our results on the plant growth-promoting abilities of VOCs produced by bacterial endophytes were confirmed in repeated experiments in $A$. thaliana. Based on these results, we hypothesized that bacterial volatiles might have a similar growth-promoting impact on other higher plants.

Effect of bacterial volatiles on tomato plant growth. Based on the previous observations of $A$. thaliana, detailed studies were carried out to test the influence of VOCs on tomato, pepper, and cucumber plant growth.
After $30 \mathrm{~d}$ of exposure of tomato plants to VOCs, significant differences were observed in shoot length, and total fresh and dry biomass. The plants exposed to VOCs were taller compared with control plants (Figs. 4 and 5). Results showed that shoot length increased by $82 \%$ in plants exposed to VOCs from isolate $\mathrm{E}$, and a $50 \%$ increase in shoot length in plants exposed to VOC from isolates B17A, A2B1, PS, PSL (Bacillus amyloliquefaciens), and Prt was recorded (Fig. 5). The detailed effects of VOCs of different bacterial endophytes on the root system of tomato plants elucidated using WinRHIZOTM analysis software are presented in Table 3.

These observations indicate that the holes made at the bottom of plastic pots allowed the exposure of roots to the volatiles produced by bacterial cultures below the root system, which affected aboveground shoots. All isolates increased root length 2fold. In addition, VOC-exposed roots had significant differences in the number of tips, forks, and crosses compared with roots of control plants (Table 3). Volatile compounds produced by isolate $\mathrm{E}$ showed the most significant and pronounced effect on the roots, with about a 2.5 -fold increase in both root length and root volume (Table 3), suggesting that VOCs produced by bacterial endophytes have a remarkable ability to
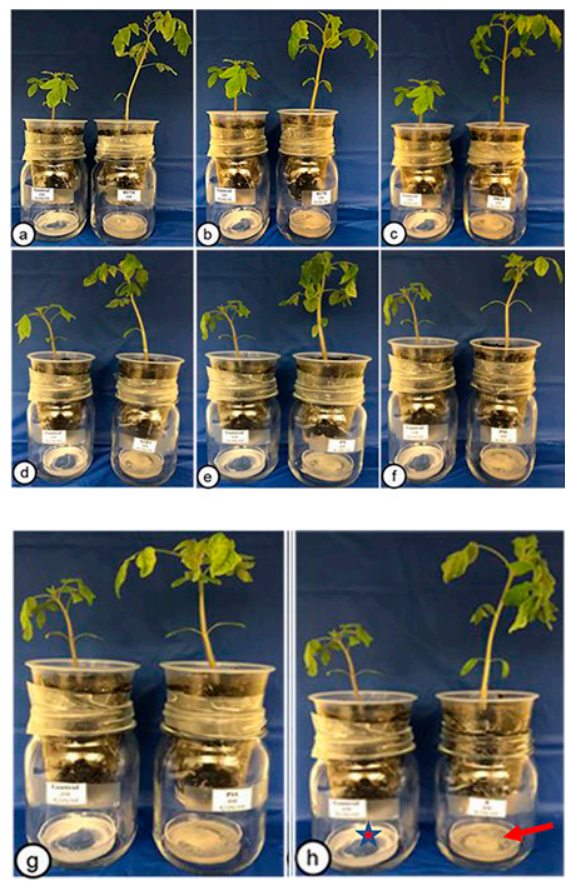

Fig. 4. Pictorial representation of soil-grown plants to assess the effect of volatile organic compounds emitted by bacterial endophytes on plant growth in tomato seedlings compared with controls with no bacteria. (a) B17A (Stenotrophomonas sp.). (b) B17B (Serratia marcescens). (c) IMC8 (Bacillus thuringiensis). (d) A2B1 (B. thuringiensis). (e) PS (B. vallismortis). (f) PSL (B. amyloliquefaciens). (g) Prt (B. subtilis). (h) E (Enterobacter sp.). Bacterial culture is indicated by an arrow. The control medium with no bacterium is indicated by a star. Similar results were obtained when the experiment was repeated.

modify the root system architecture of exposed plants. Furthermore, the overall effect of volatile compounds produced by endophytes on plant growth showed that plant height, and total fresh and dry biomass of tomato seedlings exposed to VOCs were significantly greater than the control treatment with no bacteria $(P<0.0001)$ (Fig. 5). Clearly, VOCs produced by bacterial endophytes support growth promotion in higher plants.

Effect of bacterial volatiles on sweet pepper and cucumber plant growth. After a 30-d exposure of sweet pepper plants to bacterial VOCs, the treated plants were consistently greener (Fig. 6), with significantly greater chlorophyll content, shoot weight, and leaf area than the untreated controls, but plant height and leaf number were unaffected significantly (Table 4). Using mixed isolates 1:1 (v/v) did not seem to have an advantage over using individual isolates (Table 4).

Cucumber seedlings exposed to volatile compounds emitted by the selected bacteria displayed significantly greener plants (Fig. 6), and chlorophyll content and leaf area were significantly greater in all treatments compared with the untreated controls (Fig. $7 b$ and c). There were no significant differences between treatments in plant height, and only treatment 


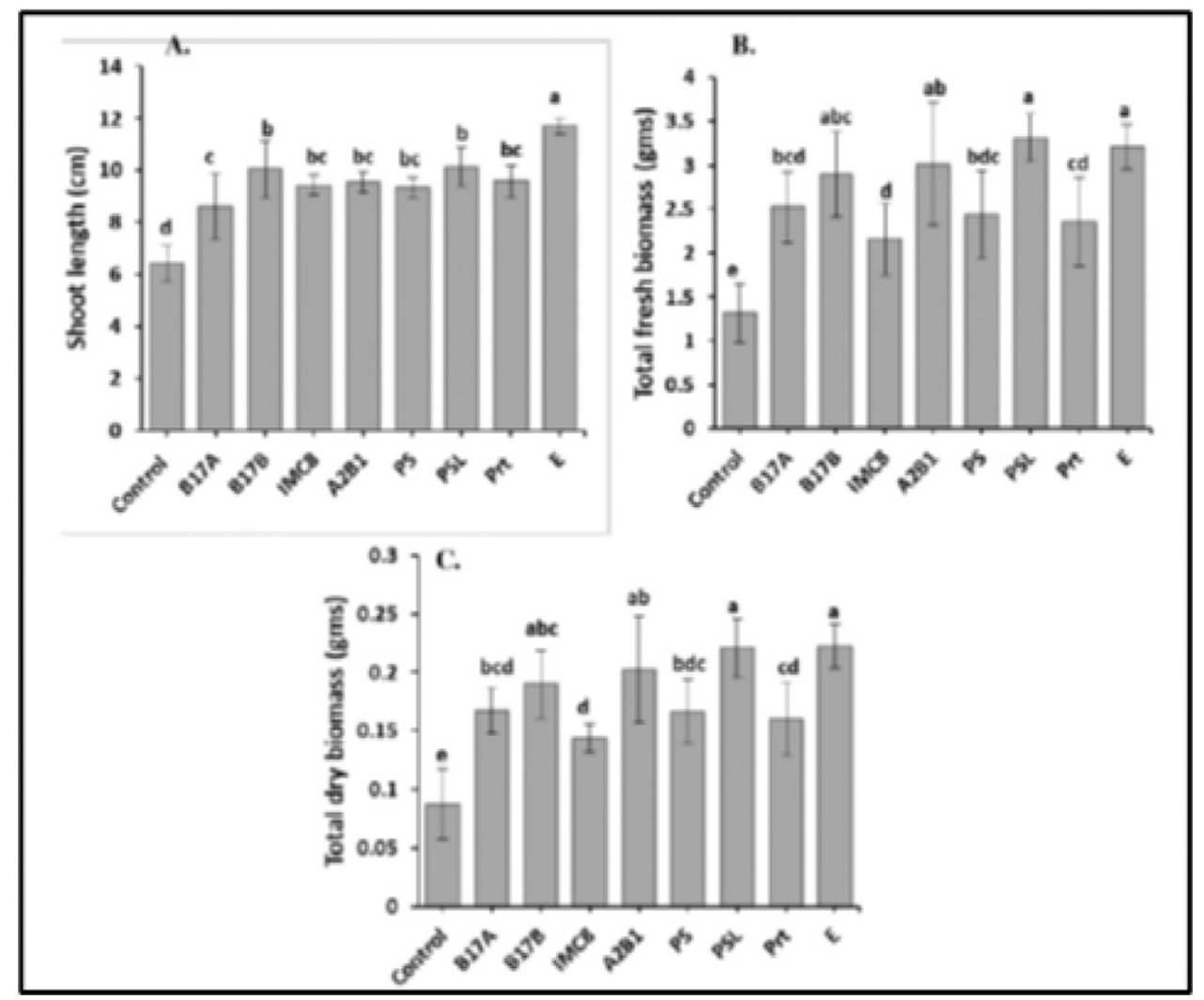

Fig. 5. Growth of tomato seedlings after $30 \mathrm{~d}$ of exposure to volatile compounds produced by bacterial endophytes. Isolates B17A (Stenotrophomonas sp.), B17B (Serratia marcescens), IMC8 (Bacillus thuringiensis), A2B1 (B. thuringiensis), PS (B. vallismortis), PSL (B. amyloliquefaciens), Prt (B. subtilis), and E (Enterobacter sp.) were measured according to (A) shoot length, (B) total fresh biomass, and (C) total dry biomass. Similar results were obtained in two experiments, with four replicates per treatment (mean $\pm \mathrm{SD}$ ). Values with the same letters on the bars indicate no significant difference according to the least significant difference test $(P \leq 0.05)$.

Table 3. Quantitative results of root analysis of tomato plants exposed to volatile compounds emitted by bacterial endophytes measured by using WinRHIZO software.

\begin{tabular}{|c|c|c|c|c|c|}
\hline \multirow[b]{2}{*}{ Endophyte } & \multicolumn{5}{|c|}{ Growth parameter ${ }^{z}$} \\
\hline & Root length (cm) & Root volume $\left(\mathrm{cm}^{3}\right)$ & NTips & NForks & Ncross \\
\hline$\overline{\mathrm{B} 17 \mathrm{~A}}$ & $174.85 \pm 36.97 \mathrm{~b}^{\mathrm{y}}$ & $0.238 \pm 0.08 \mathrm{a}-\mathrm{c}$ & $228 \pm 48 \mathrm{bc}$ & $1,402 \pm 351 \mathrm{~b}-\mathrm{d}$ & $51 \pm 9 \mathrm{~cd}$ \\
\hline B17B & $228.15 \pm 45.44 \mathrm{ab}$ & $0.27 \pm 0.06 \mathrm{ab}$ & $313 \pm 58 \mathrm{ab}$ & $2,041 \pm 594 \mathrm{ab}$ & $94 \pm 33 a b$ \\
\hline $\mathrm{A} 2 \mathrm{~B} 1$ & $222.25 \pm 25.49 \mathrm{ab}$ & $0.23 \pm 0.05 \mathrm{~b}-\mathrm{d}$ & $300 \pm 23 \mathrm{ab}$ & $1,870 \pm 324 \mathrm{a}-\mathrm{c}$ & $98 \pm 12 \mathrm{ab}$ \\
\hline PS & $211.08 \pm 32.69 \mathrm{~b}$ & $0.22 \pm 0.07 \mathrm{~b}-\mathrm{d}$ & $285 \pm 59 \mathrm{ab}$ & $1,829 \pm 253 \mathrm{a}-\mathrm{c}$ & $102 \pm 12 a b$ \\
\hline PSL & $272.27 \pm 55.21 \mathrm{a}$ & $0.3 \pm 0.08 \mathrm{ab}$ & $297 \pm 66 \mathrm{ab}$ & $2,052 \pm 616 \mathrm{ab}$ & $112 \pm 43 \mathrm{a}$ \\
\hline
\end{tabular}

${ }^{\mathrm{z}}$ Data are the mean \pm SD of four replicates per treatment.

${ }^{\mathrm{y}}$ Values with the same letters in each column indicate no significant difference according to the least significant difference test at $P \leq 0.05$ for bacterial isolates B17A (Stenotrophomonas sp.), B17B (Serratia marcescens), IMC8 (Bacillus thuringiensis), A2B1 (B. thuringiensis), PS (B. vallismortis), PSL (B. amyloliquefaciens), Prt (B. subtilis), and E (Enterobacter sp.). Similar results were obtained when the experiment was repeated.

with isolate PSL was better than the control in improving root length (Fig. 7).

\section{Discussion}

The bacterial endophytes used in our study were selected for biological control of fungal pathogens on diverse plants (Irabor and Mmbaga, 2017; Joshua and Mmbaga, 2020; Mmbaga et al., 2008, 2016, 2018; Rotich et al., 2019). In addition to disease control, the endophytes exhibited plant growth promotion. Studies reported in this article have shown that the selected endophytes produce volatile compounds that promoted plant growth in terms of root and shoot biomass for all four plant species evaluated, and exhibited a distinct influence on root architecture and increased the formation of lateral roots on $A$. thaliana and tomato plants. These observations support reports on stimulated plant growth by VOCs from Bacillus, Pseudomonas, Enterobacter, and Streptomyces (Asari et al., 2016; Cordovez et al., 2015, 2018; D'Alessandro et al., 2014; Park et al., 2015; Ryu et al., 2003; Tahir et al., 2017a, 2017b). Previous studies on the selected bacterial isolates have shown their in vitro and in vivo antagonistic abilities against diverse pathogens, including $P$. capsici (Bhusal and Mmbaga, 2020; Irabor and Mmbaga, 2017), but the role of VOCs on disease suppression was not evaluated. Syed-Ab-Rahman et al. (2019) reported that VOCs produced by soil bacterial isolates exerted anti-oomycete effects, inhibiting $P$. capsici in vitro, and promoted both plant growth and root system development, suggesting a need to evaluate the role of VOCs in the antagonistic effects of the selected endophytes.

Most studies on the effect of microbial volatiles on plant growth have focused on $A$. 
thaliana, and studies at cellular, molecular, and metabolic levels have verified the effect of VOCs in A. thaliana. However, more

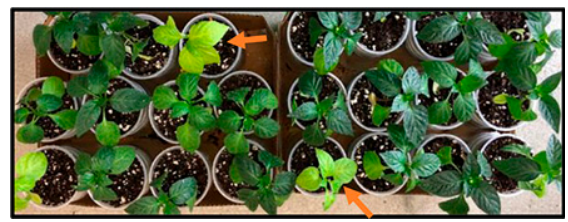

Fig. 6. Growth of sweet pepper seedlings showing greener color after $30 \mathrm{~d}$ of exposure to volatile compounds emitted by selected bacterial isolates compared with untreated controls (arrows). studies are needed to elucidate the mode of action on plant growth of other crop plantsespecially on vegetable, fruit, and forage crops - to boost the use of microbial products as a sustainable strategy to reduce the use of chemical products. Volatiles produced by microorganisms are known to be low-molecular weight VOCs that diffuse freely in aboveground and belowground environments (Schulz-Bohm et al., 2017; Vespermann et al., 2007). The VOCs are known to act as stimuli that activate a wide range of signals that regulate physiological processes and cellular effects on exposed plants (Kai et al., 2016; Paola and Quiroz, 2018). Some reports have shown that the VOCs can induce plant growth by modulation of essential nutrients, hormonal balance, metabolism, and sugar concentrations (Schulz-Bohm et al., 2017). Although the phenomenon of VOCs as growth inducers is not well understood, reports on exposure of $A$. thaliana to volatiles from $B$. subtilis GB03 revealed activation of Fe uptake, increased photosynthesis through $\mathrm{Fe}$ assimilation, and increased photosynthetic capacity and chlorophyll content (Kai et al., 2016; Paola and Quiroz, 2018; Schulz-Bohm et al., 2017). Few studies on genetic, proteomic, and metabolic analyses have shown that VOCs play a role in the regulation of phytohormone levels, metabolic pathways, and nutrition levels. Our observations suggest that

Table 4. Summarized results of plant growth analysis of sweet pepper plants exposed to volatile compounds emitted by bacterial endophytes under growth chamber conditions.

\begin{tabular}{lccccccc}
\hline & \multicolumn{5}{c}{ Growth parameters } \\
\cline { 2 - 7 } Bacterial endophytes & Chlorophyll content & $\mathrm{Ht}(\mathrm{cm})$ & Shoot wt $(\mathrm{g})$ & Root wt $(\mathrm{g})$ & No. of leaves & Root length $(\mathrm{cm})$ & Leaf area $\left(\mathrm{cm}^{2}\right)$ \\
\hline IMC8 & $39.60 \mathrm{ab}^{\mathrm{z}}$ & 8.06 & $4.02 \mathrm{a}$ & 0.63 & 10.8 & 15.00 & $38.53 \mathrm{a}-\mathrm{c}$ \\
PS & $45.66 \mathrm{ab}$ & 10.98 & $4.84 \mathrm{a}$ & 2.68 & 11.8 & 22.37 \\
PSL & $52.32 \mathrm{a}$ & 8.66 & $3.63 \mathrm{ab}$ & 1.71 & 11.6 & 20.67 \\
IMC8 + PS & $40.74 \mathrm{ab}$ & 9.75 & $4.44 \mathrm{a}$ & 1.90 & 11.6 & $22.06 \mathrm{a}$ \\
IMC8 + PSL & $27.02 \mathrm{bc}$ & 10.01 & $3.45 \mathrm{ab}$ & 1.92 & 9.6 & 21.76 & $42.02 \mathrm{~b}-\mathrm{d}$ \\
PS + PSL & $42.14 \mathrm{ab}$ & 9.60 & $3.55 \mathrm{ab}$ & 0.96 & 10.8 & $25.72 \mathrm{~cd}$ \\
IMC8 + PS + PSL & $33.92 \mathrm{ab}$ & 9.74 & $4.78 \mathrm{ab}$ & 2.18 & 11.6 & 20.47 \\
Control & $7.76 \mathrm{c}$ & 8.72 & $2.11 \mathrm{~b}$ & 2.34 & 8.60 & $35.35 \mathrm{~b}-\mathrm{d}$ \\
7 & & &
\end{tabular}

${ }^{\mathrm{z}}$ Values with different letters in each column indicate significant differences according to the least significant difference test at $P \leq 0.05$ for bacterial isolates IMC8 (Bacillus thuringiensis), PS (B. vallismortis), PSL (B. amyloliquefaciens), and water (control). Similar results were obtained when the experiment was repeated.
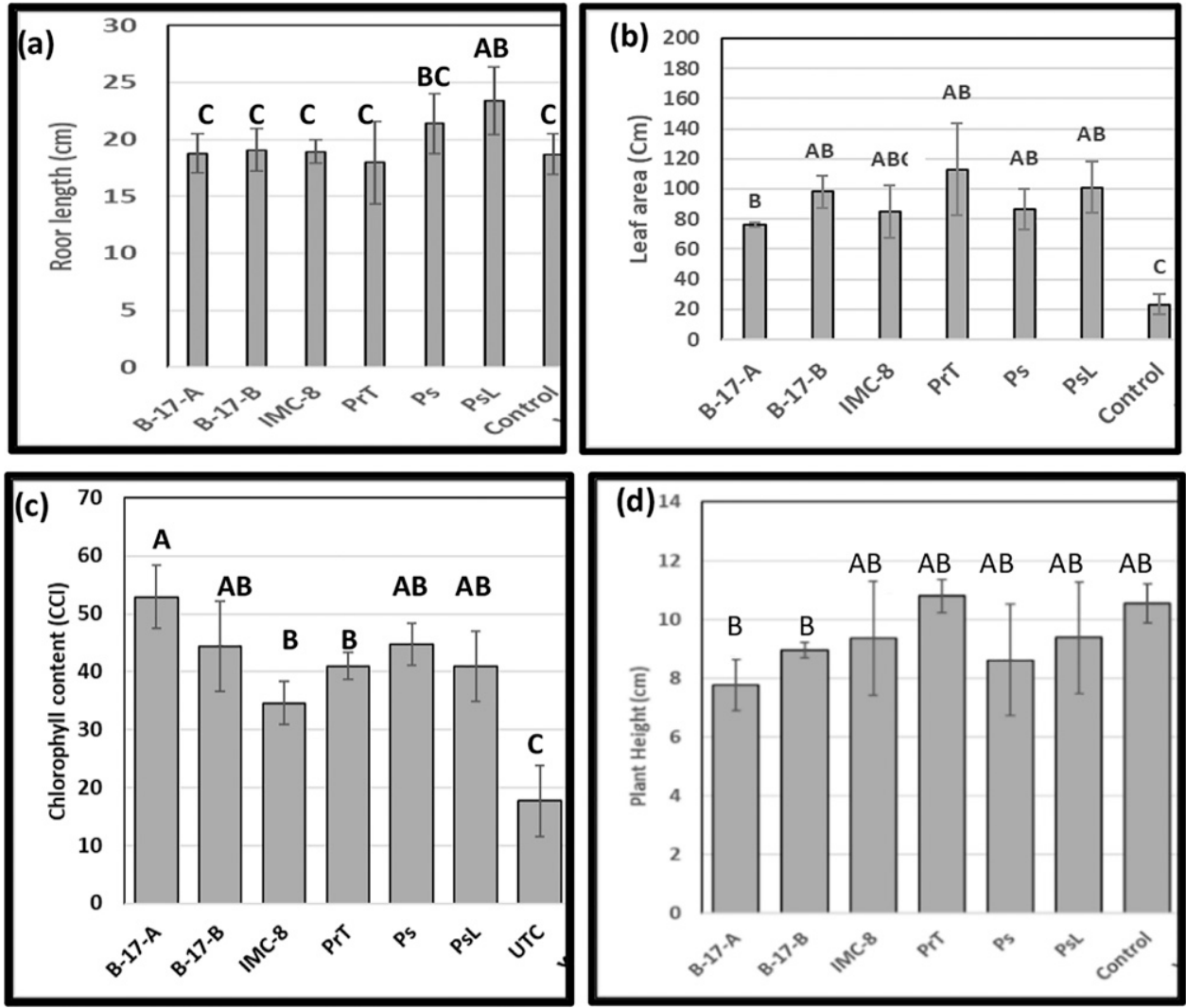

Fig. 7. Growth of cucumber seedlings after $30 \mathrm{~d}$ of exposure to volatile compounds produced by bacterial isolates B17A (Stenotrophomonas sp.), B17B (Serratia marcescens), IMC8 (Bacillus thuringiensis), Prt (B. subtilis), PS (B. vallismortis), and PSL (B. amyloliquefaciens) compared with the untreated control (UTC) measured according to (a) root length, (b) leaf area, (c) chlorophyll content, and (d) plant height, which had no significant differences. Similar results were obtained in two experiments, with four replicates per treatment (mean \pm SD). Values with the same letters on the bars indicate no significant difference according to the least significant difference test $(P>0.05)$. 
the VOCs may have influenced the regulation of metabolic pathways at phytohormone and nutritional levels, and increased photosynthesis and possibly Fe assimilation, causing the increase in plant greenness and chlorophyll content (Table 4, Fig. 6). Although more studies are needed first to identify the VOCs emitted by the selected biological control agents (BCAs), our study results have shown that the selected bacterial endophytes produce volatile compounds that promote growth in A. thaliana and tomato, sweet pepper, and cucumber plants.

The effect of bacterial volatiles was studied on plants without any direct contact between the plants and the bacterial cells using a triplate arrangement for A. thaliana, and was confirmed in tomato, pepper, and cucumber plants anchored above the bacterial endophytes, exposing the seedlings roots to VOCs, with no direct contact between bacterial cells and the plants. The production of VOCs largely depends on growth medium composition; the MS growth media used our $A$. thaliana study was adopted from previous studies by Ryu et al. (2003, 2004) and Zou et al. (2010). Other studies have used different growth media, including tryptic soy agar, potato dextrose agar, King's B agar, water agar, yeast peptone dextrose agar, malt extract agar, complete medium agar, and minimal medium agar (Asari et al., 2016; Blom et al., 2011b; Vespermann et al., 2007). Results from our study displayed a more than 2fold increase in biomass in plants exposed to Stenotrophomonas (B17A) and Serratia (B17B) isolates (Fig. 2). These results contrast with those of Vespermann et al. (2007) who reported more than $80 \%$ growth inhibition in $A$. thaliana plants exposed to VOCs from Pseudomonas, Stenotrophomonas, and Serratia species. Differences in the effect of VOCs on plant growth reported in our study compared with results of Vespermann et al. (2007) may have been influenced by the growth media used. Notwithstanding this, our results show that VOCs emitted by the selected bacterial endophytes had a distinct influence on root architecture, and increased the formation of lateral roots in A. thaliana and tomato plants exposed to VOCs (Table 3, Fig. 3).

The soil-grown seedling plants showed a significant increase in biomass after $30 \mathrm{~d}$ of exposure to VOCs with all tested bacterial endophytes, with the most prominent effect being from isolates PSL and E on both shoot and root growth in tomato plants. These results are consistent with reports from Tahir et al. (2017a, 2017b), who reported significant increases in growth of both tomato and tobacco plants when roots were exposed to volatiles produced by the B. subtilis SYST2 isolate. However, in our study, the VOC effects on pepper plant height and leaf number were insignificant (Table 4), which suggests that plant species specificity is possible and requires additional examination. Cordovez et al. (2018) reported that plant growth promotion can be tissue specific. Their study showed that exposure of roots to volatiles from eight strains of Microbacterium sp. induced significant increases in shoot and root biomass in $A$. thaliana, but differed in their effects on root architecture. Similarly, Microbacterium volatiles led to an enhanced root and shoot biomass of lettuce and tomato, and biomass increases for plants exposed only briefly to volatiles from strain EC8 before transplantation of the seedlings to soil. However, shoot exposure resulted in no or less growth promotion.

The consistently greener sweet pepper and cucumber plants exposed to VOCs compared with the untreated control (Figs. 6 and 7) may have resulted from the potential role of VOCs in regulating phytohormone levels, metabolic pathways, and nutrition levels, with increased photosynthesis and possibly $\mathrm{Fe}$ assimilation. A genome-wide transcriptome analysis of $A$. thaliana seedlings exposed to volatiles emitted by Microbacterium strains showed upregulation of genes involved in assimilation and transport of sulfate and nitrate (Cordovez et al., 2018). This indicates that growth promotion was most likely via modulation of sulfur and nitrogen metabolism. Although the bacterial treatments for tomato and pepper assays differed slightly, and the growth parameters measured in different plant species were slightly different (Tables 1 and 2), the plant growth promotion displayed in all four plant species tested showed that the selected bacterial endophytes generated volatile compounds that enhanced different parameters of plant growth. Notwithstanding that mixed BCAs were evaluated on pepper only, results showed that using mixed isolates 1:1 (v/v) did not have an advantage over using individual isolates (Table 4). These observations show a need for additional studies to understand more fully BCA-host plant interactions.

\section{Conclusion}

In conclusion, our findings demonstrate that selected bacterial endophytes produced volatile compounds that played a significant role in plant growth promotion. Our results also show that VOCs can alter the morphology of above- and belowground parts of the plant. Further analyses of the mechanism of growth promotion and identification of VOCs are required.

\section{Literature Cited}

Asari, S., S. Matzen, M.A. Petersen, S. Bejai, and J. Meijer. 2016. Multiple effects of Bacillus amyloliquefaciens volatile compounds: Plant growth promotion and growth inhibition of phytopathogens. FEMS Microbiol. Ecol. 92: Fiw070.

Blom, D., C. Fabbri, E.C. Connor, F.P. Schiestl, D.R. Klauser, T. Boller, L. Eberl, and L. Weisskopf. 2011a. Production of plant growth modulating volatiles is widespread among rhizosphere bacteria and strongly depends on culture conditions. Environ. Microbiol. 13:3047-3058, doi: 10.1111/j.1462-2920.2011.02582.x.

Blom, D., C. Fabbri, L. Eberl, and L. Weisskopf. 2011b. Volatile-mediated killing of Arabidopsis thaliana by bacteria is mainly due to hydrogen cyanide. Appl. Environ. Microbiol. 77:10001008, doi: 10.1128/AEM.01968-10.

Bhusal, B. and M.T. Mmbaga. 2020. Biological control of phytophthora blight and growth promotion in sweet pepper by Bacillus species. Biol. Control 150:104373, doi: 10.1016/j.bio control.2020.104373.

Cordovez, V., V.J. Carrion, D.W. Etalo, R. Mumm, H. Zhu, P.G. van Wezel, and J.M. Raaijmakers. 2015. Diversity and functions of volatile organic compounds produced by Streptomyces from a disease-suppressive soil. Front. Microbiol. 6:1081, doi: 10.3389/fmicb.2015 01081.

Cordovez, V., S. Schop, K. Hordijk, H. Dupré de Boulois, F. Coppens, I. Hanssen, J.M. Raaijmakers, and V.J. Carrión. 2018. Priming of plant growth promotion by volatiles of root-associated Microbacterium spp. Appl. Environ. Microbiol. 84(22):e01865-18, doi: 10.1128/AEM. 01865-18.

D’Alessandro, M., M. Erb, J. Ton, A. Brandenburg, D. Karlen, J. Zopfi, and T.C.J. Turlings. 2014. Volatiles produced by soil-borne endophytic bacteria increase plant pathogen resistance and affect tritrophic interactions. Plant Cell Environ. 37(4):813-826, doi: 10.1111/ pce. 12220

Fan, D., S. Subramanian, and D.L. Smith. 2020. Plant endophytes promote growth and alleviate salt stress in Arabidopsis thaliana. Sci. Rep. 10:12740, doi: 10.1038/s41598-020-69713-5.

Han, S.H., S.J. Lee, J.H. Moon, K.H. Park, K.Y. Yang, B.H. Cho, K.Y. Kim, Y.W. Kim, M.C. Lee, and A.J. Anderson. 2006. GacS-dependent production of 2R, 3R-butanediol by Pseudomonas chlororaphis $\mathrm{O} 6$ is a major determinant for eliciting systemic resistance against Erwinia carotovora but not against Pseudomonas syringae pv. tabaci in tobacco. Mol. Plant Microbe Interact. 9:924-930.

Irabor, A. and M.T. Mmbaga. 2017. Evaluation of selected bacterial endophytes for biocontrol potential against phytophthora blight of bell pepper (Capsicum annuum L.). J. Plant Pathol. Microbiol. 8:424.

Joshua, J.O. 2017. Management of root rot disease in snap beans using biological control agents. Tennessee State University, Nashville, TN. $\mathrm{PhD}$ Diss. Dissertation Abstracts Intl., Vol. 7810(E), Section B.

Joshua, J.O. and M.T. Mmbaga. 2020. Potential biological control agents for soil-borne fungal pathogens in Tennessee Snap Bean Farms. HortScience 55:988-994, doi: 10.21273/HORSCI14081-19.

Kai, M., U. Effmert, and B. Piechulla. 2016. Bacterial-plant-interactions: Approaches to unravel the biological function of bacterial volatiles in the rhizosphere. Front. Microbiol. 7:108.

Kanchiswamy, C., M. Malnoy, A.L. Khan, B.A. Halo, A. Elyassi, S. Ali, K. Al-Hosni, J. Hussain, A. Al-Harrasi, and I. Lee. 2016. Indole acetic acid and ACC deaminase from endophytic bacteria improves the growth of Solanum lycopersicum. Electron. J. Biotechnol. 21: $58-64$.

Khan, A.L., B.A. Halo, A. Elyassi, S. Ali, K. AlHosni, J. Hussain, A. Al-Harrasi, and I. Lee. 2016. Indole acetic acid and ACC deaminase from endophytic bacteria improves the growth of Solanum lycopersicum. Electronic J. Biotechnol. 21:58-64.

Li, X., X. Geng, R. Xie, L. Fu, J. Jiang, L. Gao, and J. Sun. 2016. The endophytic bacteria isolated from elephant grass (Pennisetum purpureum Schumach) promote plant growth and 
enhance salt tolerance of hybrid Pennisetum. Biotechnol. Biofuels 9:190.

Li, H.B., R.K. Singh, P. Singh, Q.Q. Song, Y.X. Xing, L.T. Yang, and Y.R. Li. 2017. Genetic diversity of nitrogen-fixing and plant growth promoting Pseudomonas species isolated from sugarcane rhizosphere. Front. Microbiol. 14(8): 1268, doi: 10.3389/fmicb.2017.01268.

Loaces, I., L. Ferrando, and A. Fernández Scavino. 2011. Dynamics, diversity and function of endophytic siderophore-producing bacteria in rice. Microb. Ecol. 61:606.

Mmbaga, M.T., S. Gurung, and A. Maheshwari. 2018a. Screening of plant endophytes as biological control agents against root rot pathogens of pepper (Capsicum annum L.). J. Plant Pathol. Microbiol. 9:435, doi: 10.4172/21577471.1000.

Mmbaga, M.T., L.M. Mackasmiel, and F.A. Mrema. 2018b. Evaluation of biological control agents for Macrophomina root rot and powdery mildew in flowering dogwood (Cornus florida L.). HortScience 53:334-336, doi: 10.21273/ HortSci12596-17.

Mmbaga, M.T., F.A. Mrema, L.M. Mackasmiel, and E. Rotich. 2016. Effect of bacteria isolates in powdery mildew control in flowering dogwoods (Cornus florida L.). Crop Prot. 89:51-57.

Mmbaga, M.T., R.J. Sauve, and F.A. Mrema. 2008. Identification of microorganisms for biological control of powdery mildew in Cornus florida. Biol. Control J. 44:67-72.

Murashige, T. and F. Skoog. 1962. A revised medium for rapid growth and bioassays with tobacco tissue cultures. Physiol. Plant. 15:473-497, doi: 10.1111/j.1399-3054.1962.tb08052.x.

Paola, F. and A. Quiroz. 2018. Microbial volatiles as plant growth inducers. Microbiol. Res. 208: 63-75, doi: 10.1016/j.micres.2018.01.002.

Park, Y.S., S. Dutta, M. Ann, J.M. Raaijmakers, and K. Park. 2015. Promotion of plant growth by Pseudomonas fluorescens strain SS101 via novel volatile organic compounds. Biochem. Biophys. Res. Commun. 461:361-365, doi: 10.1016/j.bbrc.2015.04.039.

Petrini, O. 1991. Fungal endophytes of tree leaves. In: J.H. Andrews and S.S. Hirano (eds.). Microbial ecology of leaves. Springer Verlag, New York, NY.

Rotich, E. 2015. Studies on bacterial biological control of powdery mildew and other fungal pathogens in Cornus florida. Tennessee State University, Nashville, TN. PhD Diss. Dissertation Abstracts Intl., Volume: 77-06(E), Section B.

Rotich, E., M.T. Mmbaga, and J.O. Joshua. 2019. Biological control of powdery mildew on Cornus florida using endophytic Bacillus thuringiensis isolate. Can. J. Plant Pathol, doi: 10.1080/07060661.2019.1641555.

Ryu, C.M., M.A. Farag, C.H. Hu, M.S. Reddy, J.W. Kloepper, and P.W. Pare. 2004. Bacterial volatiles induce systemic resistance in Arabidopsis. Plant Physiol. 134:1017-1026.

Ryu, C., M.A. Farag, C. Hu, M.S. Reddy, H. Wei, P.W. Pare, and J.W. Kloepper. 2003. Bacterial volatiles promote growth in Arabidopsis. Proc. Natl. Acad. Sci. USA 100:4927-4932.
Schulz-Bohm, K., L. Martín-Sánchez, and P. Garbeva. 2017. Microbial volatiles: Small molecules with an important role in intra and interkingdom interactions. Front. Microbiol. 8:2484, doi: 10.3389/fmicb.2017.02484.

Syed-Ab-Rahman, S.F., L.C. Carvalhais, E.T. Chua, F.Y. Chung, P.M. Moyle, E.G. Eltanahy, and P.M. Schenk. 2019. Soil bacterial diffusible and volatile organic compounds inhibit Phytophthora capsici and promote plant growth. J. Sci. Total Environ. 692:267-280, doi: 10.1016/j.scitotenv.2019.07.061.

Tahir, H.A.S., Q. Gu, H. Wu, W. Raza, A. Hanif, L. Wu, M.V. Colman, and X. Gao. 2017a Plant growth promotion by volatile organic compounds produced by Bacillus subtilis SYST2. Front. Microbiol. 8:171, doi: 10.3389/ fmicb.2017.00171.

Tahir, H.A.S., Q. Gu, H. Wu, W. Raza, A. Safdar, Z. Huang, F.U. Rajer, and X. Gao. 2017b. Effect of volatile compounds produced by Ralstonia solanacearum on plant growth promoting and systemic resistance inducing potential of Bacillus volatiles. BMC Plant Biol. 17:133 doi: 10.1186/s12870-017-1083-6.

Vespermann, A., M. Kai, and B. Piechulla. 2007. Rhizobacterial volatiles affect the growth of fungi and Arabidopsis thaliana. Appl. Environ. Microbiol. 73:5639-5641, doi: 10.1128/ aem.01078-07.

Zou, C., Z. Li, and D. Yu. 2010. Bacillus megaterium strain XTBG34 promotes plant growth by producing 2-pentylfuran. J. Microbiol. 48:460-466, doi: $10.1007 / \mathrm{s} 12275-010-0068$. 